\title{
A South American Embalmed Head
}

\section{Rudy Lallo', Roberto Testi², Massimo Massimelli3, Raffaella Bianucci4, Rosa Boano4, Emma Rabino Massa ${ }^{4}$}

I Fondazione Pinna Pintor \& Studio Futura,Via Amerigo Vespucci, 6I, 10100 Turin, Italy

2 Director of the Operational Unit of Legal Medicine, ASL 3,Via Pacchiotti, 4, I0I46 Turin, Italy

3 Legal Medicine Office, C.so Massimo D’Azeglio, 60/g, I0100, Turin, Italy

4 University of Turin, Department of Animal and Human Biology, Laboratory of Anthropology,

Via Accademia Albertina, 13, 10123 Turin, Italy

KEY WORDS: South American mummy, CT scanning, endoscopy, electron microscopy, histology

\section{Abstract}

The embalmed head of a young South American man is housed in the Museum of Anthropology and Ethnography of the University of Turin. This man, who suffered a violent facial trauma, was intentionally beheaded after his death, and his head was embalmed.

The aim of this study was to determine the age at death, the cause of death and the embalming techniques by means of $C T$ scanning, 3D reconstruction, $X$-rays, histology, endoscopy and scanning electron microscopy followed by microanalysis.

\section{Introduction}

The embalmed head of a South American man was discovered in the stores of Turin's Museum of Anthropology and Ethnography. The specimen, whose dating and provenience are unknown, presents a violent facial trauma. The man was intentionally beheaded after his death and his head was immediately embalmed (Figs. 1, 2) (Vreeland and Cockburn 1980).

The preliminary results of a multidisciplinary study are presented.

\section{Material and Methods}

A spiral CT scan performed with a multidetector spiral CT (Philips Aura, Netherlands) yielded 215 2-mm thick slices with a reconstruction interval of $\mathrm{I} \mathrm{mm}$. Two further series of CT scans to acquire further details of the skull provided, respectively, I 35 and I $23 \mathrm{I}-\mathrm{mm}$ thick slices with a reconstruction interval of $0,5 \mathrm{~mm}$.

The images were transferred to a Vitrea 2 workstation (Version 3.3.I,Vital Images, USA) for post-processing and $3 \mathrm{D}$ reconstruction.

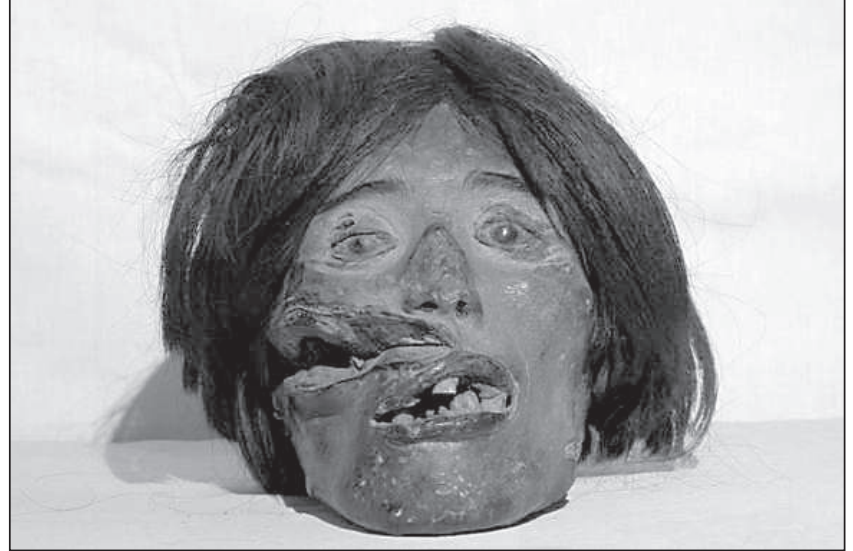

Fig. 1 - The South American embalmed head.

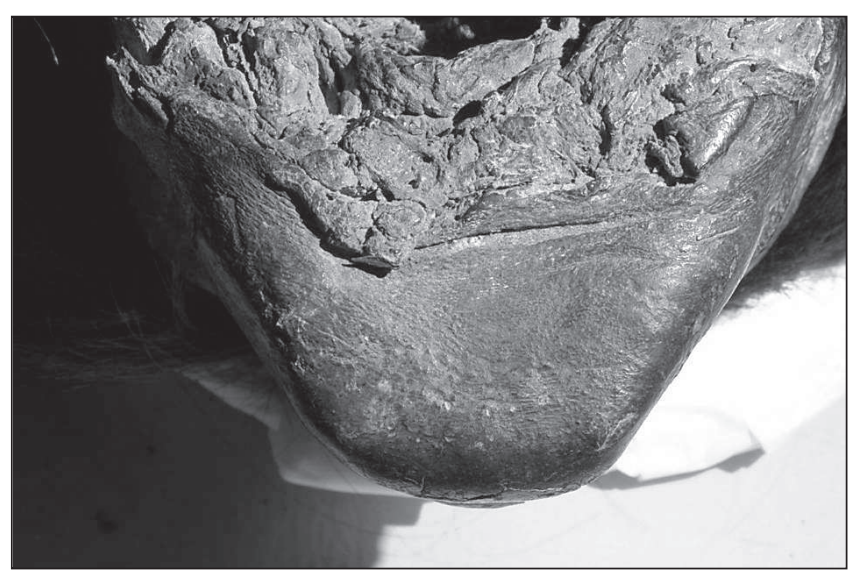

Fig. 2 - Evidence of intentional beheading.

We then carried out a cranial endoscopy, entering the skull through the foramen magnum. A virtual cranial endoscopy was also performed. Both endoscopies revealed a yellowish-white crystalline material completely filling the interior of the skull and forming a huge radiopaque area. Two samples of this material were taken with a log at $7 \mathrm{~cm}$ and $12,5 \mathrm{~cm}$ from the foramen magnum. The samples were observed under a stereomicroscope and analysed with a LEO I430VP scanning electron microscope (LEO Electron Microscopy Ltd, Cambridge, UK) with a Link ISIS 300 dispersive $\mathrm{X}$-ray analyser (EDX) equipped with the Cameo $^{\mathrm{TM}}$ program for $\mathrm{X}$-ray colour imaging (Oxford 
Instruments, High Wycombe, UK) directly in variable pressure (Torre and Mattutino, 2000).

Two tissue samples from the right cheek (at the level of the wound) and one tissue sample from the submandibular area were obtained from biopsies. The fragments were observed by scanning electron microscopy (SEM) and then subjected to histological and immunohistochemical analyses (Ruffer, 1909; Sandison, 1955; Macadam and Sandison, 1969; Barraco, 1978; Curry et al., 1979; Wick et al., 1980;

Krypczyk and Tapp, 1986).

The samples were rehydrated, fixed and routinely embedded in paraffin wax blocks by hand.

Various histochemical methods (haematoxylin-eosin, Grocott, MSB trichrome, periodic acid-Shiff reaction [PAS]) were used to identify the individual tissue components. Antibodies against several connective tissue proteins (anticollagen type I, II, III and elastin) were applied and localised using biotinylated secondary antibodies and StreptABComplex conjugated to horseradish peroxidase.

\section{Results}

The 3D reconstruction showed that the head belonged to a man in his twenties at the time of death.

At the level of the wound, there are fractures of the right maxillary wall and right mandibular condyle (Fig. 3). These lesions do not communicate with the oropharynx, which indicates that internal drowning was not the cause of death. This is confirmed by the fact that no blood infiltration was observed histologically at the level of the wound.

The scans also revealed a radiopaque material filling the interior of the skull and forming a cap at the parietal level. Endoscopy showed that this material is a yellowish-white substance similar to resin (Fig. 4).

Two samples of this material, taken at different depths, were observed by scanning electron microscopy (SEM) followed by microanalysis. The microanalysis spectrum showed that it is composed mainly of barium-sulphur, leadsulphur and lead (Fig. 5).

When we examined the tissues microscopically after histochemical staining, we were able to identify derma with thick, differently orientated type I and II collagen fibres and a pilum-sebaceous unit consisting of a tiny follicle surrounded by voluminous lobules of a sebaceous gland. Among the dermal collagen bundles, we identified a plain tubular sudoriferous eccrinous gland, as well as a transversely sectioned piliferous follicle.

At higher magnification (450x), we identified the various structures forming the follicle; starting from the core, we observed the pilum with stalk and cuticle, the internal sheath of the pilum and the follicular epidermis (Fig. 6 a-b). Successful histochemical staining was obtained for collagen, loose connective tissue with blood vessels, epidermis, derma, pilum-sebaceous unit and sudoriferous gland. Positive immunostaining was seen as a deposit of brown or red reaction product depending on the method used. The preservation of antigens in this embalmed specimen

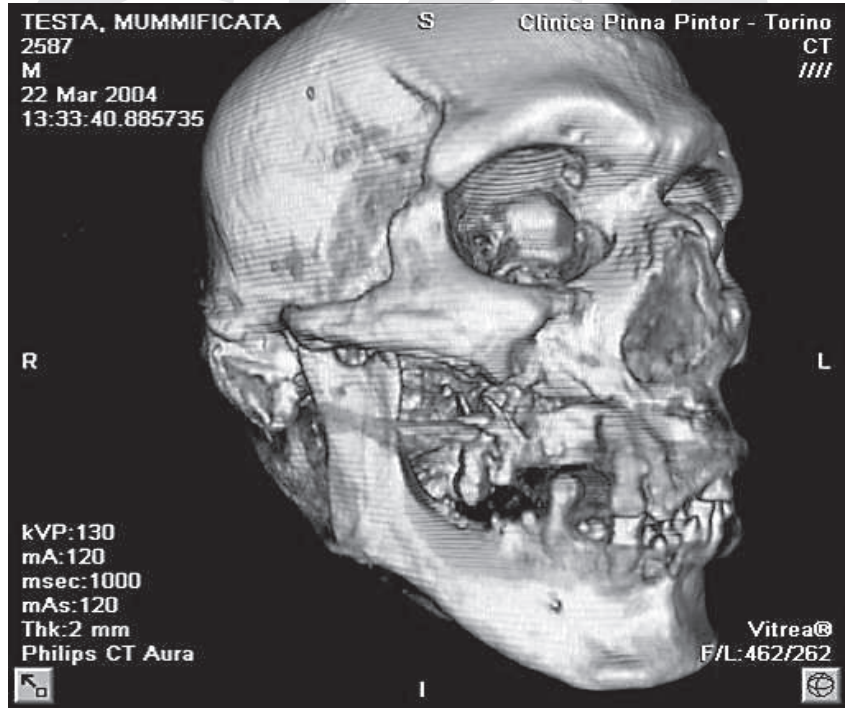

Fig. 3 - 3D reconstruction results: fractures of the right maxillary wall and right mandibular condyle at the level of the wound.

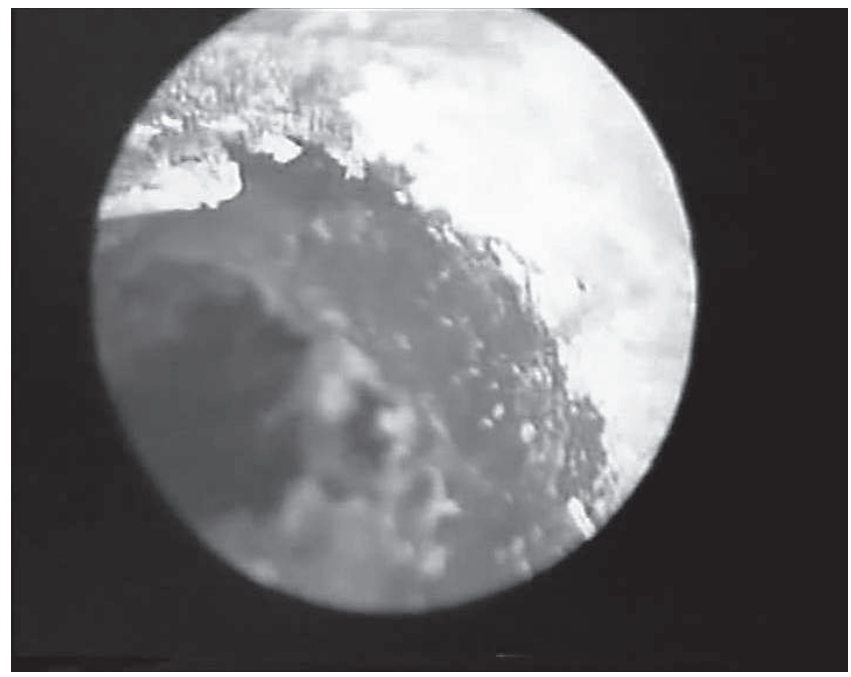

Fig. 4 - Endoscopy results.

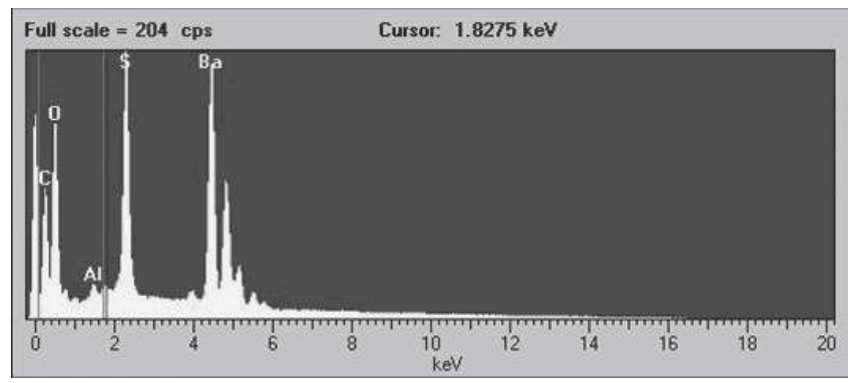

Fig. 5 - Microanalysis spectrum of the material filling the interior of the skull.

was much better than expected. Therefore, we are currently developing other methods to process the tissues for the application of immunolocalisation techniques.

Further analyses will be performed to date the specimen, to obtain information about its geographical provenience and to learn more about the embalming techniques used to achieve the good state of preservation. 

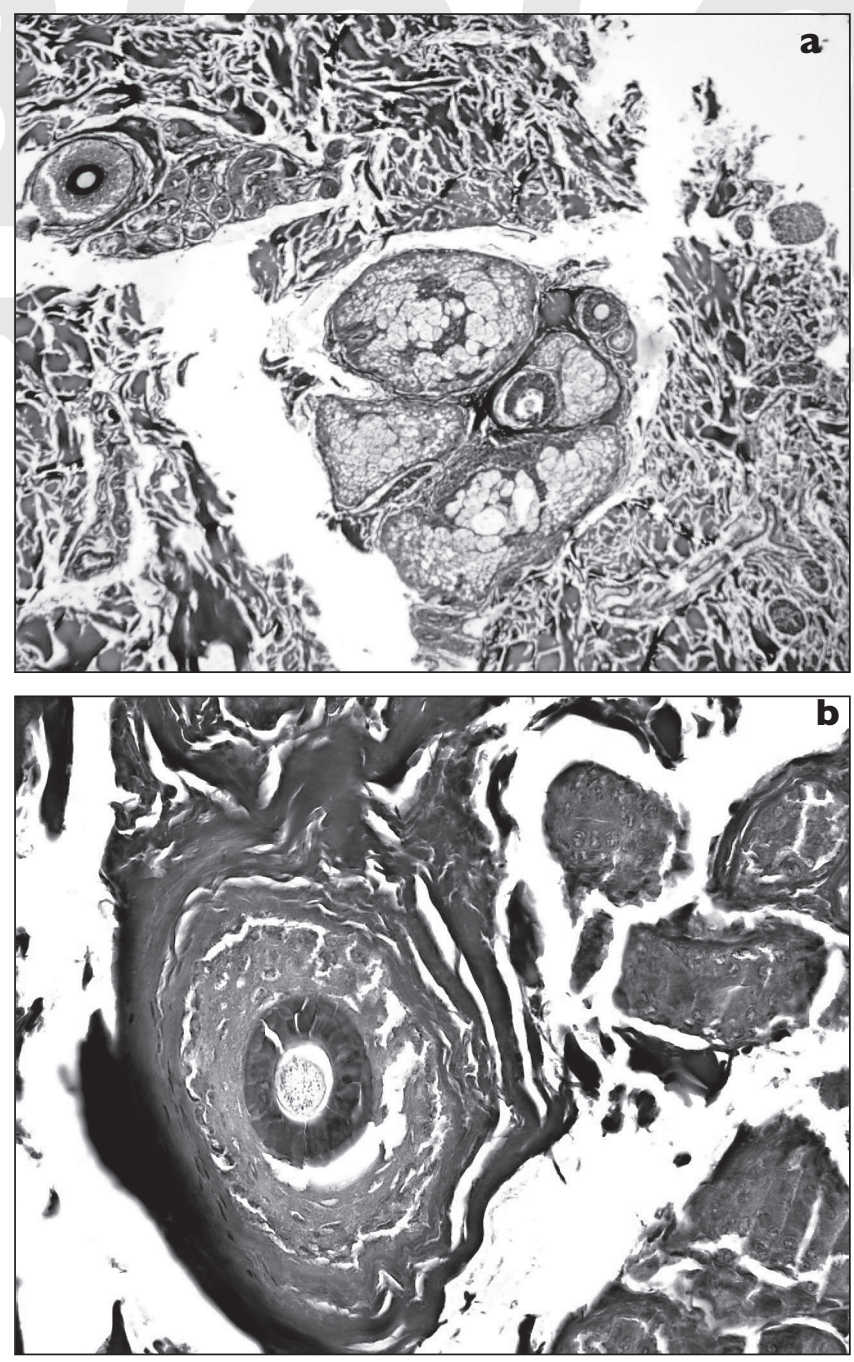

Fig. 6 - Example of immunolocalisation in the embalmed tissues: $a-A$ pilum-sebaceous unit surrounded by voluminous lobules of $a$ sebaceous gland and a plain tubular sudoriferous eccrinous gland; $b$-The structures forming the follicle. Magnification: $a-250 x, b-450 x$.

\section{Literature Cited}

Barraco RA. 1978. Preservation of proteins in mummified tissues. Am. J. Phys. Anthropol. 48: 487-49I.

Curry A, Anfield C, Tapp E. 1979, Electron microscopy of the Manchester mummies. In: David AR (ed), Manchester Museum Mummy Project. Manchester: Manchester University Press.

Krypczyk A, Tapp E. 1986. Immunohistochemistry and electron microscopy of Egyptian mummies. In: David A. R. (ed), Science in Egyptology.

Macadam RF, Sandison AT. 1969. The electron microscope in paleopathology. Med Hist. 13: 81-5.

Ruffer AM. 1909. Preliminary note on the histology of Egyptian mummies. B.M.J: 1005.

Sandison AT. 1955. The histological examination of mummified material. Stain Technol. 30: 277.

Torre C, Mattutino G. 2000. Application of true color X-ray vision for electron microscopy in fired bullets and gunshot residue investigation. Journal of Forensic Sciences, 45 (4): 865-87I.

Vreeland Jr JM, Cockburn A. 1980. Mummies of Peru. In: Cockburn, Aidan and Eve (eds), 1980. Mummies, Diseases and Ancient Cultures. Cambridge: Cambridge University Press 1980, pp. I35-174.

Wick G, Haller M,Timpl R, Cleve H, Ziegelmayer G. 1980. Mummies from Peru. Demonstration of antigenic determinants of collagen in the skin. Int. Arch.Allergy Applied Immunol. 62: 76-80.

\section{Acknowledgements}

The Authors wish to thank Prof. Carlo Torre and Dr. Grazia Mattutino of the University of Turin, Department of Anatomy, Pharmacology and Legal Medicine, Laboratory of Forensic Sciences, and Dr. Stefano Taraglio,

Director of the Pathological Anatomy Unit,A.S.O. Maria Vittoria-Amedeo di Savoia, Turin, for their collaboration. 